\title{
Effect of self-etching ceramic primer on bond strength of zirconia-reinforced lithium silicate ceramics
}

\author{
Awad, Mohamed M ; Al Jeaidi, Zaid A ; Almutairi, Nader ; Vohra, Fahim ; Özcan, Mutlu ; Alrahlah, Ali
}

\begin{abstract}
This study evaluated the effect of self-etching ceramic primer (SECP) on shear bond strength (SBS) of zirconia-reinforced lithium silicate (ZLS) ceramics. Two hundred and seventy block-specimens of two types of ZLS ceramics and one type of lithium disilicate (LS) ceramics were prepared. Ninety blocks of each material were divided into three groups $(\mathrm{n}=30)$, namely group 1: no surface treatment (control), group 2: hydrofluoric acid (HF), silane-based primer (S), and group 3: SECP. Resin cement was applied, and light-cured for build-up. Shear bond strength (SBS) test was used. Half of the bonded specimens $(n=15)$ were tested after storage in distilled water for $24 \mathrm{~h}$, whereas the other half were tested after 5000 thermo-cycles. The failure modes were evaluated using scanning electron microscope (SEM). The SBS values for samples treated with SECP and HF + S within the respective materials were statistically comparable $(\mathrm{p}>0.05)$. Thermocycling significantly reduced the SBS $(\mathrm{p}<0.05)$ for all ceramic materials in groups 2 and 3. Mixed failure followed by adhesive failure were the most common failure modes in groups 2 and 3, whereas pretest failure was only detected in group 1. Considering the limitations of the study, with respect to in vitro bond strength, the SECP is an alternative for the conditioning of internal surface of glass ceramics.
\end{abstract}

DOI: https://doi.org/10.1080/01694243.2019.1661156

Posted at the Zurich Open Repository and Archive, University of Zurich

ZORA URL: https://doi.org/10.5167/uzh-198839

Journal Article

Accepted Version

Originally published at:

Awad, Mohamed M; Al Jeaidi, Zaid A; Almutairi, Nader; Vohra, Fahim; Özcan, Mutlu; Alrahlah, Ali (2020). Effect of self-etching ceramic primer on bond strength of zirconia-reinforced lithium silicate ceramics. Journal of Adhesion Science and Technology, 34(1):91-101.

DOI: https://doi.org/10.1080/01694243.2019.1661156 


\title{
Effect of Self-Etching Ceramic Primer on bond strength of Zirconia-Reinforced Lithium Silicate Ceramics
}

\author{
Mohamed M. Awad ${ }^{1}$, Zaid A. Al jeaidi ${ }^{1}$, Nader Almutairi ${ }^{1}$, Fahim Vohra ${ }^{2.3}$, Mutlu Özcan ${ }^{4}$,
}

\begin{abstract}
Ali Alrahlah ${ }^{5,3^{*}}$
${ }^{1}$ Department of Conservative Dental Sciences, Prince Sattam Bin Abdulaziz University, College of Dentistry, AlKharj 11942, Saudi Arabia.dr.mm.awad@hotmail.com

${ }^{1}$ Department of Conservative Dental Sciences, Prince Sattam Bin Abdulaziz University, College of Dentistry, Alkharj, Saudi Arabia. dr.aljeaidi@gmail.com

${ }^{1}$ Department of Conservative Dental Sciences, Prince Sattam Bin Abdulaziz University, College of Dentistry, Alkharj, Saudi Arabia. Nader.Ridn@gmail.com

${ }^{2}$ Department of Prosthetic Dental Sciences, College of Dentistry, King Saud University, Riyadh, Saudi Arabia,

${ }^{3}$ Engineer Abdullah Bugshan research chair for Dental and Oral Rehabilitation, king Saud University, Riyadh 11545, Saudi Arabia.E-mail: fahimvohra@yahoo.com

${ }^{4}$ Dental Materials Unit, Center for Dental and Oral Medicine, University of Zürich, Zürich, Switzerland.

${ }^{5}$ Department of Restorative Dental Sciences, College of Dentistry, King Saud University, Riyadh 11545, Saudi Arabia. aalrahlah@ksu.edu.sa
\end{abstract}

*Correspondence: Ali Alrahlah, Department of Restorative Dental Sciences, College of Dentistry, King Saud University, P.O. Box 60169, Riyadh 11545, Saudi Arabia. Email: aalrahlah@ksu.edu.sa Tel: +966-11-467-7420; Fax: +966-11-467-9016. 


\begin{abstract}
This study evaluated the effect of self-etching ceramic primer (SECP) on shear bond strength (SBS) of zirconia-reinforced lithium silicate (ZLS) ceramics. Two-hundred-and-seventy blockspecimens of two types of ZLS ceramics and one type of lithium disilicate (LS) ceramics were prepared. Ninety blocks of each material were divided into three groups $(n=30)$, namely group 1 : no surface treatment (control), group 2: hydrofluoric acid (HF), silane-based primer (S), and group 3: SECP. Resin cement was applied, and light-cured for build-up. Shear bond strength (SBS) test was used. Half of the bonded specimens $(n=15)$ were tested after storage in distilled water for 24 h, whereas the other half were tested after 5000 thermo-cycles. The failure modes were evaluated using scanning electron microscope (SEM). The SBS values for samples treated with SECP and $\mathrm{HF}+\mathrm{S}$ within the respective materials were statistically comparable $(\mathrm{p}>0.05)$. Thermocycling significantly reduced the SBS $(\mathrm{p}<0.05)$ for all ceramic materials in groups 2 and 3 . Mixed failure followed by adhesive failure were the most common failure modes in groups 2 and 3, whereas pretest failure was only detected in group 1 . Considering the limitations of the study, with respect to in vitro bond strength, the SECP is an alternative for the conditioning of internal surface of glass ceramics.
\end{abstract}

Keywords: Ceramic, Bond strength, CAD/CAM, Self-etching ceramic primer, Thermocycling 


\section{Introduction}

The use of computer-aided design/computer-aided manufacturing (CAD/CAM) technology in dentistry is increasing and is replacing the traditional techniques of fabricating dental restorations $[1,2]$. CAD/CAM restorative materials are mainly dental ceramics and indirect composite resins [3]. CAD/CAM glass ceramics include feldspathic, leucite reinforced, lithium disilicate (LS), and zirconia-reinforced lithium silicate (ZLS) ceramics [4]. Despite the improved mechanical properties of LS ceramics, their clinical application and survival rates have limitations [5, 6]. Manufacturers have attempted to develop polycrystalline-reinforced glass ceramics to overcome these limitations [5]. These new reinforced-glass ceramics contain lithium meta-silicates as the main crystalline phase in a zirconia-reinforced matrix and are present in a fully or partially crystallized state $[5,7,8]$. Compared to LS ceramics, ZLS ceramics exhibit superior fracture toughness, flexural strength, elastic modulus less, and edge chipping $[7,9]$.

The quality of bonding is critical to the long-term success of ceramic restorations $[10,11]$. The specific type of surface treatment needed for ceramic materials depends on their individual composition [12]. Adhesive bonding to glass ceramics conventionally involves etching with hydrofluoric acid (HF), followed by silane-based primer (S) to enhance their physical and chemical bond using methacrylate-based resin materials [13]. ZLS are primarily glass ceramics; thus, HF etching followed by silane (S) priming is recommended by manufacturers of ZLS materials. However, HF is a toxic and hazardous material $[14,15]$. In addition, excessive application of HF potentially leads to deterioration of the mechanical properties of glass ceramics [16]. Multiple alternatives for ceramic etching have been investigated; however, none have yielded outcomes that are comparable to HF etching $[17,18,19,20]$. Self-etching ceramic primer (SECP) has been 
proposed to combine the effects of $\mathrm{HF}$ and $\mathrm{S}$, and it offers a safer and less technique-sensitive surface treatment compared to HF etching [21,22]. The influence of SECP on bonding of conventional glass ceramics has been investigated. Multiple studies have reported comparable outcomes in the use of SECP and conventional surface treatments when employed for surface treatment of glass ceramics $[21,22,23]$. However, it has also been suggested that the effect of SECP in the bonding of ceramics may well be influenced by the material composition and crystalline structure [24]. In addition, to our knowledge, the effect of SECP on bonding of ZLS ceramic has not yet been investigated. It is hypothesized that SECP surface treatment of ZLS ceramic will yield bond strength values comparable to those obtained from HF and S. Therefore, the aim of this study is to evaluate the effects of SECP and conventional surface treatment (HF and S) on the shear bond strength of resin cement to of ZLS and LS ceramics.

\section{Materials and methods}

\subsection{Specimen preparation}

Preformed blocks of each ceramic material [Celtra Duo (ZLS), VITA Suprinity (ZLS), and IPS e.max CAD (LS)] were sectioned to prepare 270 blocks, (90 blocks for each material) with dimensions of $6 \times 6 \times 3 \mathrm{~mm}$ using a low-speed cutting saw (Isomet, Buehler Ltd., USA; model number 111280) with a 4-inch circular diamond wheel (MetLab Technologies Limited, UK) under water coolant. The prepared blocks were polished for 2 min using \#600 silicon carbide paper discs (CrbiMet ${ }^{\circledR}$ Abrasive Discs, BUEHLER, Lake Bluff, Illinois, USA) mounted on a grinding machine (Automata, Jean Wirtz, Dusseldorf, Germany) at $300 \mathrm{rev} / \mathrm{min}$ under running water. The prepared blocks were ultrasonically cleaned in isopropyl alcohol for $5 \mathrm{~min}$ in an ultrasonic bath (Bransonic CPXH heated ultrasonic bath, Emerson Electric Co., St. Louis, USA) and air-dried for 20 s. The IPS e.max CAD and VITA SUPRINITY prepared blocks were sintered according to the 
manufacturer's instructions. All blocks were embedded in self-cured acrylic resin, polished and ultrasonically cleaned following the previously described protocol. Table 1 presents details of the materials used in this study.

\subsection{Bonding procedures}

The specimens in each material were randomly divided into three groups $(n=30)$, to which different bonding strategies were applied. The following surface treatments were performed on the ceramic specimens:

Group 1 (Control): no surface treatment.

Group 2: HF (VITA ceramics etch) was applied, followed by S priming (Porcelain Primer) according to the manufacturer's instructions (Table 1).

Group 3: SECP was applied to ceramic materials according to the manufacturer's instructions (Table 1).

A silicon mold (Ø: $3 \mathrm{~mm}$; height: $3 \mathrm{~mm}$ ) was constructed to fit on the ceramic surface, to perform resin cement (Variolink esthetic dual cure Ivoclar Vivadent, Schaan, Liechtenstein) buildup. Light curing was performed for $40 \mathrm{~s}$ using a dental curing light (Elipar ${ }^{\text {tm }}$ S10 LED Curing Light, 3M ESPE, MN, USA) operated at $1100 \mathrm{~mW} / \mathrm{cm}^{2}$ measured using a digital radiometer (Marc resin calibrator, Blue light analytics Inc, Nova Scotia, Canada). After removing the mold, the resin cement build-up was light-cured for additional $40 \mathrm{~s}$ at distance of $1 \mathrm{~mm}$ (Table 1). Half of the bonded specimens $(\mathrm{n}=15)$ of each group were tested after storage in distilled water for $24 \mathrm{~h}$ at 37 ${ }^{\circ} \mathrm{C}$, whereas the other half were subjected to thermocycling (5000 cycles, THE-1100, SD Mechatronik GmbH, Germany). Each cycle included placing the bonded specimens in distilled water bath at $5{ }^{\circ} \mathrm{C}$ and $55^{\circ} \mathrm{C}$ for $30 \mathrm{~s}$ each, with $5 \mathrm{~s}$ interval between baths.

\subsection{Shear bond strength (SBS) test}


The cross-sectional area of each bonded resin cement build-up was measured using a digital caliper. A notched chisel attached to the universal testing machine with a load cell of $5 \mathrm{kN}$ (Instron 5965, Instron Corporation, Norwood, MN, USA) was used at a cross-speed of $0.5 \mathrm{~mm} / \mathrm{min}$ to apply shear force at the ceramic-resin interface until debonding occurred. The types of bond failure were analyzed using a scanning electron microscope (SEM) (JSM-6610LV, JEOL Ltd., Tokyo, Japan) at $\times 15$ magnification operated at $20 \mathrm{kV}$ at a working distance of $8 \mathrm{~mm}$. The failure modes were classified as adhesive, cohesive in the ceramic, cohesive in the resin cement, and mixed (adhesive failure together with cohesive failure in the cement).

\subsection{Surface topography evaluation}

Six blocks were prepared from each ceramic material for surface topography examination following the previously mentioned protocol. Surface treatment was performed as indicated in Table 2, except for S application. The surface-treated blocks of all groups were gold-coated using a sputter coater (fine coat ion sputter JFC-1100, JEOL Ltd., Tokyo, Japan) for $180 \mathrm{~s}$ at $40 \mathrm{~mA}$, then mounted onto coded brass stubs and examined using SEM at $\times 5000$ magnification operated at $15 \mathrm{kV}$ at a working distance of $8 \mathrm{~mm}$.

\subsection{Statistical Analysis}

The data obtained was assessed for normality using the Kolmogorov-Smirnov test. Twoway ANOVA followed by one-way ANOVA were performed to compare the shear bond strength values of all the study groups. Tukey-Kramer multiple comparison post-hoc test and independent t-tests were employed to compare the shear bond strength values of individual groups.

\section{Results}

The data obtained was normally distributed. The mean and standard deviations of SBS for all the study groups are presented in Table 2. The SBS values of the control samples (group 1: no 
surface treatment) were significantly lower compared to those of the surface treated ceramic samples (groups 2 and 3) with and without thermocycling. Thermocycling significantly reduced $(p<0.05)$ the SBS for all material groups in both HF and SECP treated specimens. In the surface treated specimens, the highest SBS was observed in ZLS (VITA Suprinity) treated with HF+S $(30.53 \pm 4.36 \mathrm{MPa})$ at $24 \mathrm{~h}$, whereas the lowest SBS was observed in ZLS (Celtra Duo) after thermocycling $(18.01 \pm 3.71 \mathrm{MPa})$. The SBS values for samples treated with SECP and HF+S within the respective materials were statistically comparable ( $p>0.05)$. The SBS values were comparable ( $p>0.05)$ in ZLS and LS ceramic specimens irrespective of the type of ceramic surface treatment ( $\mathrm{SECP}$ or $\mathrm{HF}+\mathrm{S})$. In terms of the $\mathrm{HF}+\mathrm{S}$ treated specimens with thermocycling, VITA Suprinity (ZLS) ceramic showed significantly higher $(\mathrm{p}<0.05)$ SBS values compared to those of Celtra Duo (ZLS) and IPS e.max CAD (LS) ceramic materials. However, in terms of the SECP treated specimens with thermocycling, both VITA Suprinity and IPS e.max CAD showed significantly higher $(\mathrm{p}<0.05)$ SBS values compared to those of Celtra Duo.

Failure mode assessment revealed different patterns, namely adhesive, cohesive in ceramic, cohesive in resin, and mixed failures. The frequencies of the failure modes and pretest failures are shown in Fig. 1. Mixed failure (Fig. 2) was the most common failure mode observed, followed by adhesive interface failures, whereas cohesive failures in ceramic and resin cement were less frequently detected. Pretest failures were observed only in group 1 at $24 \mathrm{~h}$ and after thermocycling.

\subsection{Surface topography}

Surface treatment with both HF and SECP for all ceramic materials tested resulted in marked surface topographic changes and increased surface micro-irregularities. Lithium metasilicate, lithium orthophosphate crystals (Figs. $3 b$ and $4 b$ ), and the more prominent Lithium disilicate (Fig. 5b) were observed after HF etching. However, compared to HF etching patterns, 
the etching patterns created by SECP (Figs. 3c, 4c, 5c) were milder as the Lithium metasilicate, Lithium orthophosphate, and Lithium disilicate crystals were less prominent. The topographic features of etched LS and ZLS were different.

\section{Discussion}

This study was designed to evaluate the effect of SECP surface treatment on the bond strength of resin cements to ZLS and LS using the SBS test. Despite the increased popularity of micro-tensile bond strength test methods [25], the SBS test is still commonly used to evaluate bonding to dental ceramics $[26,27]$. The SBS test assembly can affect the result of bond strength measurement [28]. In this study, a notched chisel was used as it can produce more uniform stress distribution compared to a knife edge chisel [29]. The effect of SECP was compared to that of HF etching in terms of etching pattern, and to HF etching and S application in terms of bond strength, which is the most commonly used bonding strategy applied to glass ceramics [30]. Adhesive resin cement was used to exclude the effect of resin cement on the bond strength obtained after surface treatments. Although construction of resin build-up may not be the primary clinical use of resin cements, it is reported in recent literature that utilized SBS test to evaluate bond strength to dental ceramics[31, 32, 33].

The SBS outcomes indicate that the application of HF+S or SECP yielded a significantly higher mean SBS compared to the control groups (no treatment). In addition, the SBS values for samples treated with $\mathrm{SECP}$ and $\mathrm{HF}+\mathrm{S}$ within the respective materials were found to be statistically comparable. Therefore, the hypothesis that SECP surface treatment of ZLS ceramic will yield bond strength values comparable to those obtained from HF and S was accepted. 
The resin cement used in this study required both micromechanical surface treatment, such as HF etching, and chemical surface treatment, such as $\mathrm{S}$ application, prior to application to glass ceramics. Less retentive surface topography (Figs. 3a, 4a, 5a) and low surface roughness were observed on the ceramic surface. This may explain the very weak mean bond strength and high pretest failures in group 1. The high SBS of group 2 can be attributed to HF etching and S application. HF etches glass ceramics by reacting with silicon dioxide, which results in dissolution of the ceramic glass phase surface [30]; furthermore, the etching process results in an enlarged surface texture and increased surface micro-irregularities $[30,34,35,36]$, increases the surface energy of the ceramic, and reduces the contact angle for bonding agents [37]. SEM examination showed marked changes in surface topography, increased surface micro-irregularities, and randomly distributed micropores in both ZLS and LS ceramics after HF etching, which may be due to dissolution of the glass phase of LS and ZLS ceramics [8, 30]. Lithium disilicate $\left(\mathrm{Li}_{2} \mathrm{Si}_{2} \mathrm{O}_{5}\right)$ crystals in LS ceramic is larger in size than lithium metasilicates $\left(\mathrm{Li}_{2} \mathrm{SO}_{3}\right)$ and lithium orthophosphates $\left(\mathrm{Li}_{3} \mathrm{PO}_{4}\right)$ in both ZLS ceramics [8]. The different topographic features of HFetched LS and ZLS may be explained by their different microstructural characterizations. In addition, $\mathrm{Li}_{2} \mathrm{SO}_{3}$ in Celtra Duo is larger than that in Vita Suprinity [8], which may explain the slight difference in the surface topographic features of both materials. Silane promotes chemical adhesion between glass ceramic and resin-based materials [38,39]. Chemical adhesion is achieved as silane molecules react with water to form silanol groups [38]. Silanol groups react with the silica surface and the monomeric ends of silane molecules react with the methacrylate groups of the resin-based materials [38].

SECP contains polyfluoride for etching and trimethoxypropyl methacrylate for silanization. Ammonium polyfluoride is an acid salt that is usually employed for etching glass and 
related silicates [24]. The high SBS values in SECP may be explained by micromechanical interlocking into the surface irregularities created. SEM examinations revealed obvious topographic changes and increased surface roughness in ZLS and LS, but with a milder etching pattern compared to HF etching. This agrees with the findings by other researchers, who reported that different etching patterns were obtained from HF and SECP for glass ceramics [21, 22, 24]. This can be explained by the milder acidity of ammonium polyfluoride contained in SECP compared to HF [24]. In addition, it has also been reported that the bond between silica and fluoride is extremely strong [40]. Therefore, the chemical affinity between silica in LS and ammonium trifluoride in SECP may enhance SECP bonding. The same phenomenon may explain the effective bonding of SECP to ZLS owing to similarities in the composition of LS and ZLS.

There is no existing standardized thermocycling protocol in the literature that can be employed in SBS studies [41]. The mean SBS of all groups decreased significantly after thermocycling. Thermocycling is known to compromise the bond strength of adhesively bonded materials [42]. During the thermocycling procedure, variations in temperature generate stresses due to mismatch in the coefficient of thermal expansion of the bonded materials, resulting in reduced bond strength [43]. Water storage and thermocycling both result in hydrolytic degradation of the ceramic/resin interface [44]. In bonding of ceramics to resin, adhesive failure is more reliable in the interpretation of bond strength values [45]. In the present study, cohesive failures were less common due to the mechanical properties of the ceramics used. Mixed failures can be explained by the high bond strength and nonhomogeneous stress distribution during the application of shear force.

\section{Conclusion}

Considering the limitations of the study, with respect to in vitro bond strength, the SECP is an alternative for the conditioning of internal surface of glass ceramics. 


\section{Acknowledgement}

The authors are grateful to the Deanship of Scientific Research, King Saud University, for

funding received through the Vice Deanship of Scientific Research Chairs, Engineer Abdullah Bugshan Research Chair for Dental and Oral Rehabilitation.

\section{Conflict of Interest}

The authors declare that they have no conflict of interest. 


\section{References}

1. Davidowitz G, Kotick PG. The use of CAD/CAM in dentistry. Dental Clinics. 2011;55:559-70.

2. Beuer F, Schweiger J, Edelhoff D. Digital dentistry: an overview of recent developments for CAD/CAM generated restorations. British dental journal. 2008;204:505.

3. Coldea A, Swain MV, Thiel N. Mechanical properties of polymer-infiltrated-ceramicnetwork materials. Dental Materials. 2013;29:419-26.

4. Li RWK, Chow TW, Matinlinna JP. Ceramic dental biomaterials and CAD/CAM technology: state of the art. Journal of prosthodontic research. 2014;58:208-16.

5. SILVA LHd, MIRANDA RBdP, FAVERO SS, LOHBAUER U, CESAR PF. Dental ceramics: a review of new materials and processing methods. Brazilian oral research. 2017;31.

6. Pieger S, Salman A, Bidra AS. Clinical outcomes of lithium disilicate single crowns and partial fixed dental prostheses: a systematic review. The Journal of prosthetic dentistry. 2014;112:22-30.

7. Elsaka SE, Elnaghy AM. Mechanical properties of zirconia reinforced lithium silicate glass-ceramic. Dental materials. 2016;32:908-14.

8. Belli R, Wendler M, de Ligny D, Cicconi MR, Petschelt A, Peterlik H, Lohbauer U. Chairside CAD/CAM materials. Part 1: Measurement of elastic constants and microstructural characterization. Dental Materials. 2017;33:84-98.

9. Chavali R, Nejat AH, Lawson NC. Machinability of CAD-CAM materials. The Journal of prosthetic dentistry. 2017;118:194-9.

10. Kassardjian V, Varma S, Andiappan M, Creugers NH, Bartlett D. A systematic review and meta analysis of the longevity of anterior and posterior all-ceramic crowns. Journal of dentistry. 2016;55:1-6.

11. Blatz M, Vonderheide M, Conejo J. The effect of resin bonding on long-term success of high-strength ceramics. Journal of dental research. 2018;97:132-9.

12. Awad M, Alqahtani H, Al-Mudahi A, Murayshed M, Alrahlah A, Bhandi S. Adhesive Bonding to Computer-aided Design/Computer-aided Manufacturing Esthetic Dental Materials: An Overview. The journal of contemporary dental practice. 2017;18:622-6.

13. Matinlinna JP, Lassila LV, Özcan M, Yli-Urpo A, Vallittu PK. An introduction to silanes and their clinical applications in dentistry. International Journal of Prosthodontics. 2004;17. 14. Meldrum M. Toxicology of hydrogen fluoride in relation to major accident hazards. Regulatory Toxicology and Pharmacology. 1999;30:110-6.

15. Lund K, Refsnes M, Ramis I, Dunster C, Boe J, Schwarze P, Skovlund E, Kelly F, Kongerud J. Human exposure to hydrogen fluoride induces acute neutrophilic, eicosanoid, and antioxidant changes in nasal lavage fluid. Inhalation toxicology. 2002;14:119-32.

16. Hooshmand T, Parvizi S, Keshvad A. Effect of surface acid etching on the biaxial flexural strength of two hot-pressed glass ceramics. Journal of Prosthodontics. 2008;17:415-9.

17. Klosa K, Boesch I, Kem M. Long-term bond of glass ceramic and resin cement: evaluation of titanium tetrafluoride as an alternative etching agent for lithium disilicate ceramics. Journal of Adhesive Dentistry. 2013;15.

18. Bona AD, Anusavice KJ, Hood JA. Effect of ceramic surface treatment on tensile bond strength to a resin cement. International Journal of Prosthodontics. 2002;15. 
19. Çömlekoğlu ME, Dündar M, Güngör MA, Şen BH, Artunç C. Preliminary evaluation of titanium tetrafluoride as an alternative ceramic etchant to hydrofluoric acid. Journal of Adhesive Dentistry. 2009;11.

20. Kukiattrakoon B, Thammasitboon K. Optimal acidulated phosphate fluoride gel etching time for surface treatment of feldspathic porcelain: on shear bond strength to resin composite. European journal of dentistry. 2012;6:63.

21. Alrahlah A, Awad MM, Vohra F, Al-Mudahi A, Al Jeaidi ZA, Elsharawy M. Effect of self etching ceramic primer and universal adhesive on bond strength of lithium disilicate ceramic. Journal of adhesion science and Technology. 2017;31:2611-9.

22. Wille S, Lehmann F, Kern M. Durability of Resin Bonding to Lithium Disilicate and Zirconia Ceramic using a Self-etching Primer. Journal of Adhesive Dentistry. 2017;19.

23. Tribst J, Anami L, Özcan M, Bottino M, Melo R, Saavedra G. Self-etching Primers vs Acid Conditioning: Impact on Bond Strength Between Ceramics and Resin Cement. Operative dentistry. 2018.

24. El-Damanhoury HM, Gaintantzopoulou MD. Self-etching ceramic primer versus hydrofluoric acid etching: Etching efficacy and bonding performance. Journal of prosthodontic research. 2018;62:75-83.

25. Braga RR, Meira JB, Boaro LC, Xavier TA. Adhesion to tooth structure: a critical review of "macro" test methods. Dental Materials. 2010;26:e38-e49.

26. van den Breemer CR, Gresnigt MM, Cune MS. Cementation of glass-ceramic posterior restorations: a systematic review. BioMed research international. 2015;2015.

27. Thammajaruk P, Inokoshi M, Chong S, Guazzato M. Bonding of composite cements to zirconia: A systematic review and meta-analysis of in vitro studies. Journal of the mechanical behavior of biomedical materials. 2018.

28. Salz U, Bock T. Testing adhesion of direct restoratives to dental hard tissue-a review. Journal of Adhesive Dentistry. 2010;12.

29. DeHoff PH, Anusavice KJ, Wang Z. Three-dimensional finite element analysis of the shear bond test. Dental Materials. 1995;11:126-31.

30. Tian T, Tsoi JK-H, Matinlinna JP, Burrow MF. Aspects of bonding between resin luting cements and glass ceramic materials. Dental materials. 2014;30:e147-e62.

31. Okutan Y, Yucel MT, Gezer T, Donmez MB. Effect of airborne particle abrasion and sintering order on the surface roughness and shear bond strength between Y-TZP ceramic and resin cement. Dental materials journal. 2018. Epub 2018/12/14.

32. Grasel R, Santos MJ, Rego HC, Rippe MP, Valandro LF. Effect of Resin Luting Systems and Alumina Particle Air Abrasion on Bond Strength to Zirconia. Oper Dent. 2018;43:282-90. Epub 2018/04/21.

33. El-Damanhoury HM, Gaintantzopoulou MD. Self-etching ceramic primer versus hydrofluoric acid etching: Etching efficacy and bonding performance. Journal of prosthodontic research. 2018;62:75-83. Epub 2017/06/28.

34. Blatz MB. Bonding protocols for improved long-term clinical success. Compendium of continuing education in dentistry (Jamesburg, NJ: 1995). 2014;35:276-7.

35. Aboushelib MN, Sleem D. Microtensile bond strength of lithium disilicate ceramics to resin adhesives. Journal of Adhesive Dentistry. 2014;16.

36. Guarda G, Correr A, Gonçalves L, Costa A, Borges G, Sinhoreti M, Correr-Sobrinho L. Effects of surface treatments, thermocycling, and cyclic loading on the bond strength of a resin cement bonded to a lithium disilicate glass ceramic. Operative dentistry. 2013;38:208-17. 
37. Della Bona A, Anusavice KJ, Mecholsky Jr JJ. Failure analysis of resin composite bonded to ceramic. Dental Materials. 2003;19:693-9.

38. Özcan M, Vallittu PK. Effect of surface conditioning methods on the bond strength of luting cement to ceramics. Dental Materials. 2003;19:725-31.

39. Della Bona A, Shen C, Anusavice KJ. Work of adhesion of resin on treated lithia disilicate-based ceramic. Dental Materials. 2004;20:338-44.

40. Kolasinski KW. Etching of silicon in fluoride solutions. Surface Science. 2009;603:1904-

11.

41. Morresi AL, D'Amario M, Capogreco M, Gatto R, Marzo G, D'Arcangelo C, Monaco A. Thermal cycling for restorative materials: does a standardized protocol exist in laboratory testing? A literature review. Journal of the mechanical behavior of biomedical materials. 2014;29:295-308.

42. Amaral FL, Colucci V, PALMA-DIBB RG, Corona SA. Assessment of in vitro methods used to promote adhesive interface degradation: a critical review. Journal of Esthetic and Restorative Dentistry. 2007;19:340-53.

43. Gale M, Darvell B. Thermal cycling procedures for laboratory testing of dental restorations. Journal of dentistry. 1999;27:89-99.

44. Roulet J, Söderholm K, Longmate J. Effects of treatment and storage conditions on ceramic/composite bond strength. Journal of Dental Research. 1995;74:381-7.

45. Della Bona A, Van Noort R. Shear vs. tensile bond strength of resin composite bonded to ceramic. Journal of Dental Research. 1995;74:1591-6. 


\section{Figure Captions}

Fig. 1 Frequency of failure modes and pretest failures (EC: IPS e.max CAD, VS: Vita Suprinity, CD: Celtra Duo, NT: No treatment, T: Thermocycling)

(EC: IPS e.max CAD, VS: Vita Suprinity, CD: Celtra Duo, NT: No treatment, T: Thermocycling)

Fig. 2 SEM micrographs x15 showing adhesive failure (a), mixed failure (b) (Black arrow: resin cement, White arrow: ceramic), and cohesive failure in ceramic (c).

Fig. 3 SEM micrographs x5000 of Celtra Duo (A), Vita Suprinity (B), and IPS e.max CAD (C): (a) no treatment, (b) HF etching, and (c) SECP application 


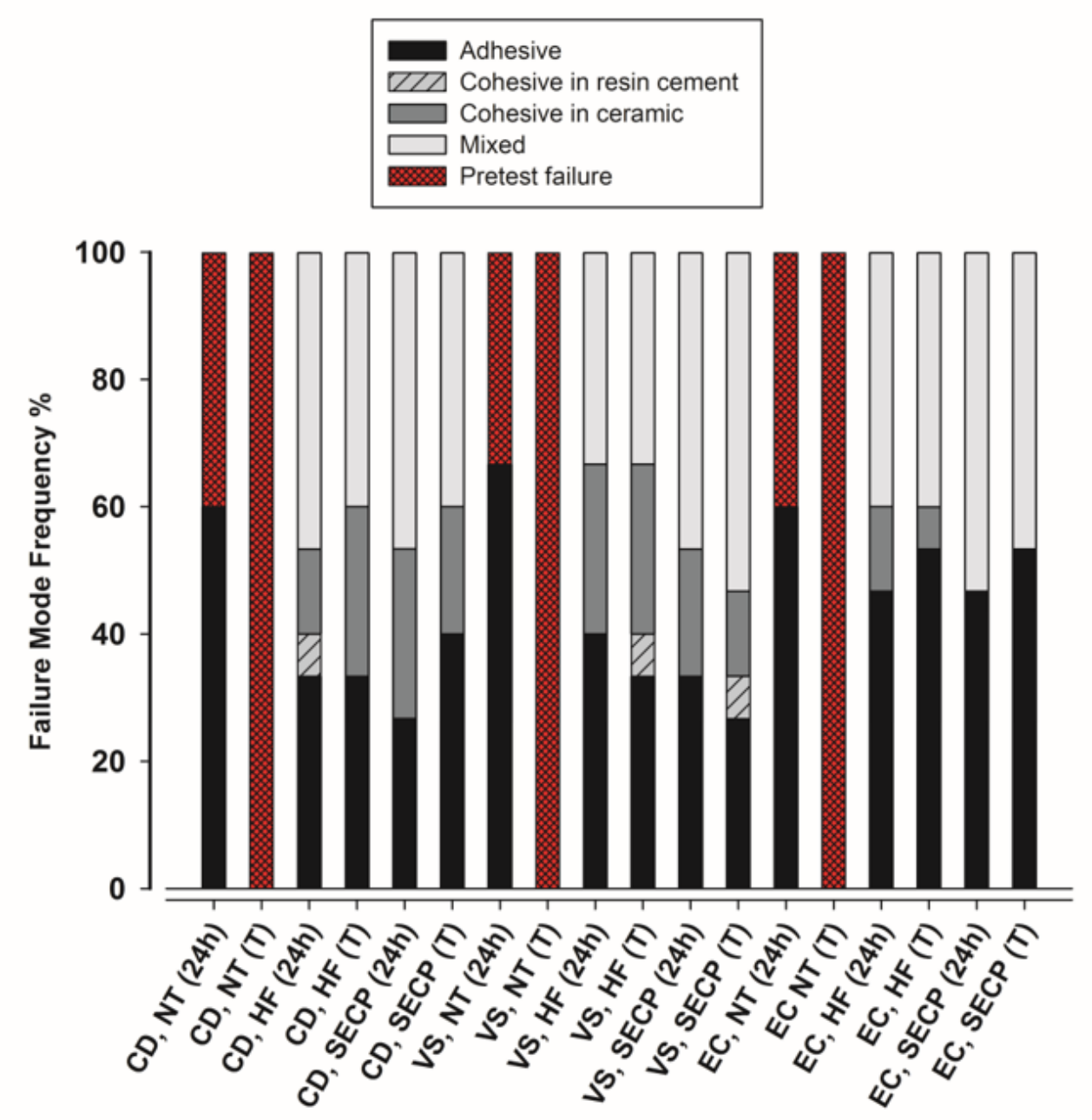

(EC: Emax CAD, VS: Vita Suprinity, CD: Celtra Duo, NT: No treatment, T: Thermocycling)

Fig.1

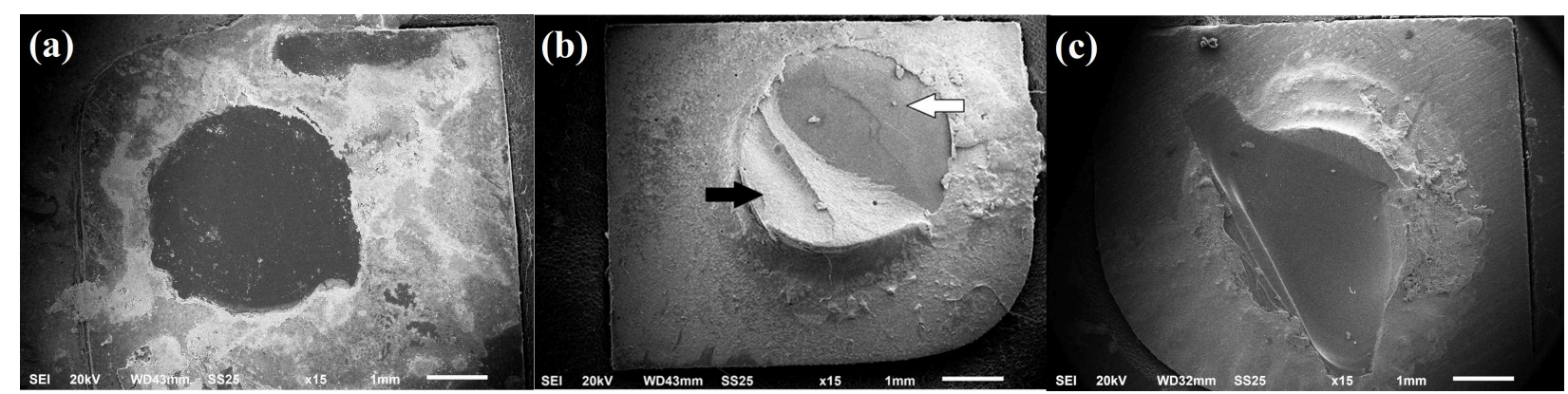

Fig. 2 


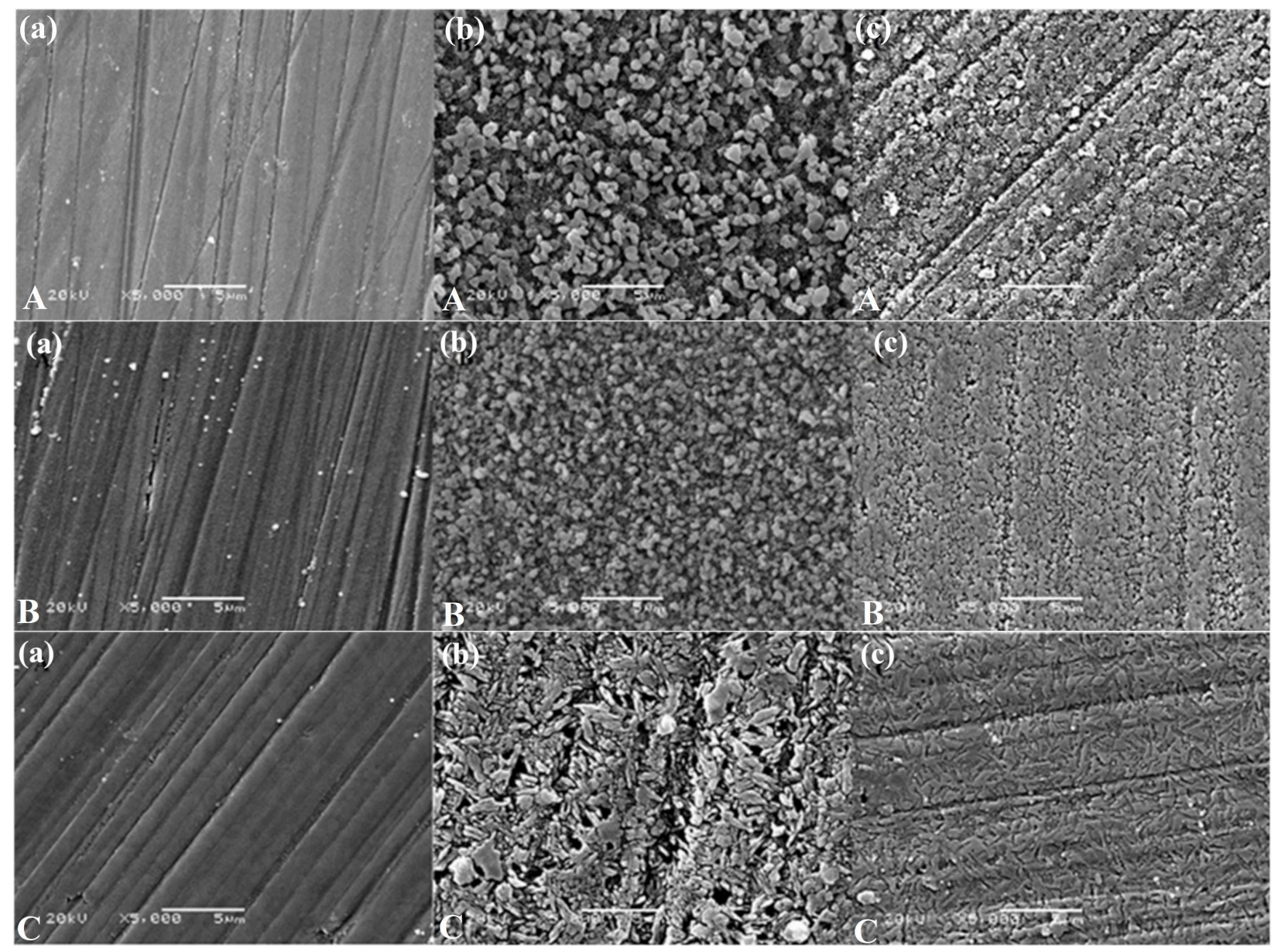

Fig. 3 


\section{$\underline{\text { Tables }}$}

Table 1 Study materials and instructions of use

\begin{tabular}{|c|c|c|}
\hline $\begin{array}{l}\text { Material, brand name, and } \\
\text { manufacturer (LOT: No.) }\end{array}$ & Composition & Instructions for use \\
\hline \multicolumn{3}{|c|}{ Zirconia-reinforced lithium silicate (ZLS) } \\
\hline $\begin{array}{l}\text { Celtra Duo } \\
\text { (DeguDent GmbH, Hanau- } \\
\text { wolfgang, Germany) } \\
\text { LOT: } 16001117\end{array}$ & Lithium silicate with $\sim 10 \% \mathrm{ZrO}_{2}$ & $\begin{array}{l}\text { Etch with HF for } 30 \mathrm{~s} \text {. } \\
\text { Rinse HF } \\
\text { Dry with air syringe } \\
\text { Apply silane }\end{array}$ \\
\hline $\begin{array}{l}\text { VITA SUPRINITY } \\
\text { (Vita Zahnfabrik, } \\
\text { Bad Säckingen, Germany) } \\
\text { LOT: } 51420\end{array}$ & $\begin{array}{l}\mathrm{SiO}_{2}, \mathrm{Li}_{2} \mathrm{O}, \mathrm{K}_{2} \mathrm{O}, \mathrm{P}_{2} \mathrm{O}_{5}, \mathrm{Al}_{2} \mathrm{O}_{3}, \\
\mathrm{ZrO}_{2}, \mathrm{CeO}_{2} \text {, pigments }\end{array}$ & $\begin{array}{l}\text { Etch with hydrofluoric acid for } 20 \mathrm{~s} . \\
\text { Rinse HF } \\
\text { Dry with air syringe } \\
\text { Apply silane }\end{array}$ \\
\hline
\end{tabular}

\section{Lithium disilicate ceramic (LS)}

IPS e.max CAD

(Ivoclar Vivadent, Schaan, Liechtenstein) LOT: W38966
$\mathrm{SiO}_{2}, \mathrm{Li}_{2} \mathrm{O}, \mathrm{K}_{2} \mathrm{O}, \mathrm{MgO}, \mathrm{P}_{2} \mathrm{O}_{5}, \mathrm{Al}_{2} \mathrm{O}_{3}$

Use self-etching ceramic primer

\section{Ceramic etchant}

VITA CERAMICS ETCH (HF)

(Vita Zahnfabrick, Bad

Säckingen, Germany)

LOT: 61900
4.7\% Hydrofluoric acid
Apply etch to surfaces requiring etching with a small disposable brush.

Remove any acid remaining on the etched surface by intensive spraying with water or by cleaning in an ultrasonic bath in distilled water.

Dry with air syringe.

\section{Silane-based primer \\ Porcelain Primer}

(S)

(BISCO, Inc. Schaumburg, IL,

USA) LOT: 1700004750

Self-etching ceramic primer (SECP)

(Ivoclar Vivadent, Schaan, Liechtenstein) LOT: V26292
Ethanol, Acetone, Silane (3methacryloxypropyltrimethoxysilane)
Brush onto etched ceramic surface

Wait for $60 \mathrm{~s}$.

Dry with air syringe.
Ammonium polyflouride, trimethoxypropyl methacrylate, solvents (alcohol and water), food colorant (fast green)
Apply on the surface using a Microbrush, agitate into the surface for $20 \mathrm{~s}$ using slight pressure. Allow to react for another $40 \mathrm{~s}$.

Thoroughly rinse off with water until the green color has been removed.

Dry with a strong stream of air for $10 \mathrm{~s}$.

\section{Resin cement}

Variolink esthetic dual cure (Ivoclar Vivadent, Schaan, Liechtenstein)

LOT: W95564
Urethane dimethacrylate, methacrylate monomers, inorganic fillers (ytterbium trifluoride and spheroid mixed oxide), initiators, stabilizers and pigments
Dispense from the automix syringe Apply directly to surface treated ceramic material Light cure 
Table 2 SBS means in MPa and standard deviations

\begin{tabular}{|c|c|c|c|c|}
\hline \multirow{2}{*}{\multicolumn{2}{|c|}{ Group }} & \multicolumn{3}{|c|}{ Ceramic materials } \\
\hline & & \multirow{2}{*}{$\begin{array}{l}\text { Celtra Duo } \\
2.23 \pm 1.60^{\mathrm{a},{ }^{*}}\end{array}$} & \multirow{2}{*}{$\begin{array}{c}\text { VITA SUPRINITY } \\
0.88 \pm 0.71^{\text {a, ** }}\end{array}$} & \multirow{2}{*}{$\begin{array}{c}\text { IPS e.max CAD } \\
0.90 \pm 0.88^{\text {a, ** }}\end{array}$} \\
\hline & $24 \mathrm{~h}$ & & & \\
\hline treatment & Thermocycling & 00.00 & 00.00 & 00.00 \\
\hline \multirow{2}{*}{$\mathbf{H F}+\mathbf{S}$} & $24 \mathrm{~h}$ & $26.36 \pm 5.07^{b, *}$ & $30.53 \pm 4.36^{b, *}$ & $28.70 \pm 6.51^{\mathrm{b}, *}$ \\
\hline & Thermocycling & $20.10 \pm 3.24 \mathrm{c}, *$ & $25.56 \pm 4.37^{\mathrm{c}, \mathrm{d},{ }^{* *}}$ & $21.32 \pm 4.14^{\mathrm{c}, *}$ \\
\hline \multirow{2}{*}{ SECP } & $24 \mathrm{~h}$ & $28.10 \pm 3.89^{\mathrm{b}, *}$ & $27.52 \pm 6.21^{\mathrm{b}, \mathrm{c}, *}$ & $26.67 \pm 4.21^{\mathrm{b}, *}$ \\
\hline & Thermocycling & $18.01 \pm 3.71^{\mathrm{c},}{ }^{*}$ & $23.37 \pm 3.09 \mathrm{~d}, * *$ & $19.85 \pm 6.04^{c, *, * *}$ \\
\hline \multicolumn{5}{|c|}{ Superscript small letters indicate significant differences (columns) $p<0.05$} \\
\hline \multicolumn{5}{|c|}{ Superscript asterisk $(*, * *)$ indicate significant differences (rows) $p<0.05$} \\
\hline
\end{tabular}

